Prof. Langley's observations ${ }^{r}$ were chiefly made with the view of shewing that the low estimates of the solar temperature which have recently been made on the basis of Dulong and Petit's formula must be wrong. Prof. Langley compared directly the heat and light received by the sun with that received by the hottest luminous source he could find. He chose the mass of liquid steel obtained in the Bessemer process. The result was that the solar heat radiation was at least eighty-seven times as strong as that of the liquid mass. It is impossible to compare this result directly with the values obtained by $\mathrm{Mr}$. Rossetti ; but a rough idea of a fair agreement may be obtained. $\mathrm{Mr}$. Rossetti fround the solar radiation to be about forty times as strong as the radiation of a lampblack body in the hottest oxyhydrogen flame he could obtain. Taking account of the emissive power of iron, we find that the radiation of the molten steel must have been a little more than half that of a black body in the oxyhydrogen flame which is possible. Prof. Langley also compared the intensity of light sent out by his two sources, and naturally found a much larger difference. We do not agree with Prof. Langley's remark that the solar light radiation is a more trustworthy indication of the total difference between the sum of all degrees of radiant energy than the heat. In fact the heat radiation is the only correct indication of the total radiant energy.

Another interesting contribution to the study of radiation was lately made by Mr. Nichols. ${ }^{2}$ Mr. Nichols heated a platinum wire to successive degrees of incandescence by an electric current, and compared the intensity of the luminous radiation in different parts of the spectrum with the incandescence of another platinum wire kept at a constant temperature by means of an electric current. There is a great experimental difficulty in determining the temperatures of the wires, and $\mathrm{Mr}$. Nichols had to content himself with measuring simply their increase in length. Matthiessen's formula will give an approximate idea of the real temperature, but it must be left to future measurements to decide how far Matthiessen's formula can be applied to high temperatures. The chief part of Mr. Nichols' work consists therefore in finding the luminous radiation of platinum, not on an absolute scale, but in terms of an incandescent platinum wire of fixed but unknown temperature. In order to reduce his measurements to an absolute scale Mr. Nichols compared the radiation of his standard with the luminous radiation of the sun, and then employed Lamansky's measurements of the heating effects of different parts of the solar spectrum. The solar spectrum is however a bad medium of comparison, owing to its discontinuous character. There is, for instance, such a strong atmospheric absorption near $\mathrm{D}$ that the radiation of the region near $D$ is seriously weakened; which weakening is entirely dependent on atmospheric conditions, and therefore makes comparisons taken at different times illusory. Thus the final curves obtained by $\mathrm{Mr}$. Nichols for the absolute radiation of platinum wire at different temperatures. show a discontinuity near $\mathrm{D}$ which is evidently produced by the above-mentioned cause, especially as Mr. Nichols did not use sunlight, but light reflected from clouds.

Mr. Niohols also tries to deduce from his experiments the fact that platinum a little below its melting point has a much larger absorbing power than at ordinary temperatures. The whole argument rests however on the assumption that the temperature of a platinum wire is the same as that of a lampblack body when the relative intensity of red and blue light given out by the lampblack body is the same as that given out by the platinum wire. That is to say, Mr. Nichols assumes that the emissive power of platinum is the same for rays of all refrangibilities. But it is evident from Mr. Nichols' own measurements that the temperature of a petwalsum flame (used by

I Proceedings of the American Academy.

2 "Ueber das von glühendem Platin ausgestrahlte Licht," E. L. Nichols. Göttingen : E. A. Huth.)
Mr. Nichols) determined in this way is found much too high. It does not require a large correction in this temperature to bring the value of reflective power of platinum at the temperature and by Mr. Nichols to the same value as that found by Provostaye and Dessains for ordinary temperatures. In the memoir of Mr. Rossetti, an idea of which we have tried to give above, this reflecting power of platinum is directly measured at a temperature of the Bunsen flame, and was found to be strikingly in accordance with the number given by Provostaye and Dessains.

ARTHUR SCHUSTER

\section{NOTE ON A CONSOIIDATED BEACH IN CEYLON}

$\triangle$ SOMEWHAT interesting consolidated beach exists $A$ on the west coast of Ceylon, a few miles to the north of Colombo. The writer had only one opportunity of visiting and examining for a short time this formation: but there are certain features in connection with it that cannot fail to be of interest, however short the examination may be. The beach extends continuously in almost a straight line for about four or five miles, and is manifestly in process of formation at the present time, as some portions of it are so soft that they can be easily crumbled in pieces by the hand, whilst others are much harder than gneiss, and can only with the greatest difficulty be fractured by means of a heavy hammer. Between these extremes are all gradations of hardness, and the ordinary shells of the coast may be found in almost every part of the beach more or less firmly embedded in the rock. The bighest part of the formation is just within reach of the waves at high tide; but it is difficult to ascertain with any degree of accuracy how far it extends into the sea, on account of the difference between high and low tide being only about two feet. The beach is seen at a glance to be composed chiefly of a faint brownish-coloured rock, with frequent strata of black material of very varied thickness and irregular shape. An examination of specimens shows that the brown rock is composed almost entirely of quartz fragments, and that it possesses only a low specific gravity $(2 \cdot 9 \mathrm{I})$, whilst the darker portions are extremely heavy as well as extremely hard. Several specimens gave a specific gravity of $3^{\circ} 9,3^{\circ} 93,3^{\circ} 94$, the dried sand, freed from its carbonate of lime by means of dilute hydrochloric acid, possessing a specific gravity of 4.32 . A microscopic examination of this sand and also of sections of the rock showed that the chief constituent, and that which gave it its dark appearance, was magnetite, corundum in various forms being also present, with here and there a fragment of quartz. One noticeable point was that the fragments of the harder constituents were in nearly every case hardworn, and rounded, whilst the quartz showed traces of recent fracture in the shape of sharp edges and angles. The size of these fragments varies very considerably, those of magnetite ranging from .005 inch to 02 inch, whilst those of quartz are much larger, frequently reaching ${ }^{\circ} \mathrm{O}_{4} \mathrm{inch}$. The corundum fragments are intermediate in size and rounded in form. It must be remembered that these specimens were taken from only one part of the formation, near the centre of its length and about the limit of high tide. In other positions the fragments will, no doubt, vary very much, the size depending in a great measure on the power of the current to carry them along the coast and up the beach. It was a matter of regret to the writer that he was not able to inspect carefully both extremities of the reef, and examine fragments from many different portions of it. The cementing material of the beach is carbonate of lime, no doubt from the coral reefs along the coast, as there is no limestone rock in the neighbourhood or along the course of the Kelani River, which debouches to the south of the reef. It is not known whence the magnetite and corundum have been derived, except that they have 
possibly come from the degradation of the gneiss rocks occurring along the coast. Although corundum is comparatively abundant in the interior of Ceylon, it has never been found in its matrix, but always either in pocket holes in streams, or in drift, intermixed with rounded pebbles of quartz. The character of the rivers in the neighbourhood of the coast apparently precludes the possibility of fragments of corundum being carried down to the sea.

A closer examination of the structure of the beach reveals the fact that the heavier particles are frequently deposited in extremely thin strata, transverse sections of which exhibit the most beautiful curves. Examples of this are seen in Figs. $I$ and 2 , which are half the natural size, the light parts representing quartz, the dark ones

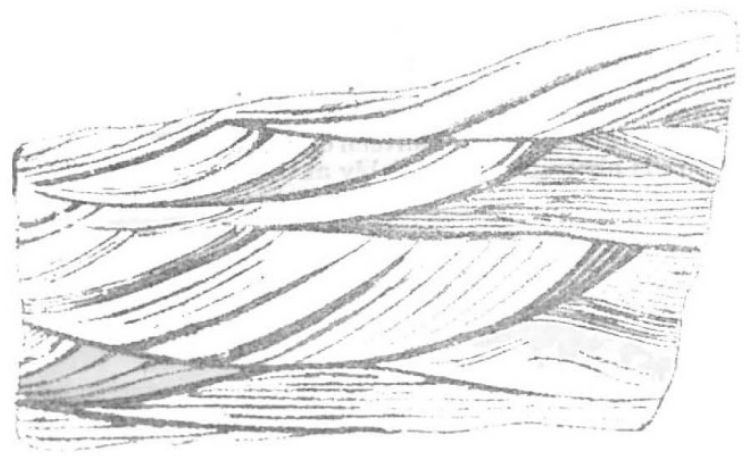

Fig. r.-About one-fourth natural size.

magnetite. The explanation of this is apparently simple. When the quartz fragments of which the larger portion of the rock is formed bave become consolidated, depressions will be formed by the heavy particles of magnetite under the influence of the waves, very much after the manner in which pocket holes are formed in the rocky beds of nearly all the mountain streams in the island. (It was in these pocket-holes that the earlier sapphires were nearly always found.) When once commenced this scouring process would go on as long as the water was sufficiently agitated to keep the fragments of magnetite in motion. Their superior weight would have a tendency to keep them in the hollows they had formed, and the carbonate of lime in the water would fix them in position as soon as they were left undisturbed by the waves. The succeeding waves

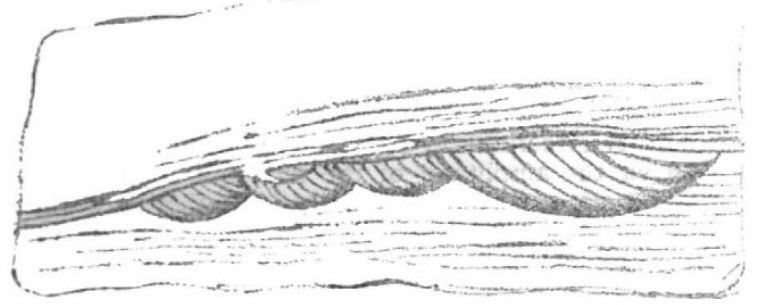

FIG. 2.-About one-fourth natural size.

hat reached the hollow would fill it chiefly with quartz fragments which would become cemented together, and the process of scouring would go on as before.

It may be noticed in explanation of the very beautiful skein-like appearance of Fig. 2, that when once a stratum of magnetite had become consolidated, it would be much less liable to be removed by the scouring process than the neighbouring quartz, on account of its superior hardness, and therefore the original shape of the basin has been retained, whilst other basins, represented by the dark lines, have been formed above it, differing only slightly in shape from the original one. Some portions of this beach are quarried for edging and coping stones which are sent to Colombo. R. ABbAY

\section{ON THE POTENTIAL DIMENSIONS OF} DIFFERENTIATED ENERG $Y^{\mathrm{I}}$

$\mathrm{T}$ his great work, which appears to be but little known $I$ in England, "Ueber die stille Bewegung hypote. tischer Körper," Prof. Hans points out that the dimensions of "ideal" matter may not only differ in degree, but also in kind. He deduces, by means of implicit reasoning from his three primitive "stations," that not only must there be space of $4,5,6, \& c$., dimensions, but also that there must be space of $-\mathrm{I},-3,-5$, \&c., dimensions, and that there may be space of $-2,-4,-6$, $\&$ c., dimensions. Pursuing Hans's train of thought further, Lobwirmski has quite recently interpreted space of $I \cdot I, I \cdot 2$, $r^{*} 3$, \&c., dimensions. Not only has fractional space been thus proved to exist, but the same philosopher has also conclusively shown that if space of $n \cdot \sqrt{-I}$ exists, it has all the properties of angular magnitude; e.g. like all partly bounded infinities (theilweise begränzte Unendlichkeiten), it is unmagnifiable.

These speculations, which are really rather more hyperphysical than metaphysical, immediately suggest the analogous kinematic considerations, and have led me to examine the potential dimensions of differentiated energy. Before pointing out the main conclusion to which I have been led, let me make quite clear the meaning of the terms employed. "Differentiated energy" is that energy which would survive if all matter were destroyed, and simultaneously re-created in such a manner that all its properties were inverted. By "potential dimension" $i$ mean the dimension which, by reason of the kinetic energy of all other dimensions, is only able to vary according to Lobwirmski's groove (Kleise).

Let us start from the idea of what is ordinarily conceived to be a Thing, and imagine the Thing itself (not its measure) to be saturated with the property $a$, after the manner in which the circle is saturated with the straight line in the spiral watch-spring (spiralförmiger Haasesprung einer $W a c h t)$. Further, let us suppose $a$ to change in such a way that all previous values of any one attribute other than those dependent on its rate of variation can be arranged in a series, the functionally alternate terms of which, up to a certain number whose value will be given by taking each turn separately, and finding to what amount its a property may, under the influence of the given "groove" exceed the $a$-property of its immediately antecedent term, represent any convenient converging series. The vigour of this change being, as usual, measured by the degree of matter affected, and also by the index of change in a given time, we have at once the simple relationship

$$
a=\left\{\begin{array}{l}
\beta \\
\gamma
\end{array}\right.
$$

Accordingly, it is obvious as one of the simplest corollaries from the above, that if we know the present position, mass, direction of motion, and velocity of a given piece of matter, we should be able within certain linifts to calculate its chemical composition.

As an example of the application of this let us suppose that the earth's satellite $M$ has the class $C$; let its direction of motion at any given time $\boldsymbol{q}$ be $\mathbf{N}$, Let its rectangular co-ordinates, at the same time, measured from the absolute zero of position, be $m-n$, and $p$. Let $O$ be its velocity, and $H$ an arbitrary constant. We have, substituting in the above equation-

$$
\mathrm{M}=\mathrm{C}_{m} \mathrm{~N}_{n} \mathrm{O}_{p} \mathrm{H}_{q}
$$

which has, at least, no closer resemblance to any other body than it has to caseine.

A. V. NUDELN

I The correspondent who has received the above letter has forwarded it to us for publication. We are not aware that the general scientific opinion in Germany is in consonance with the results reached in the letter. 